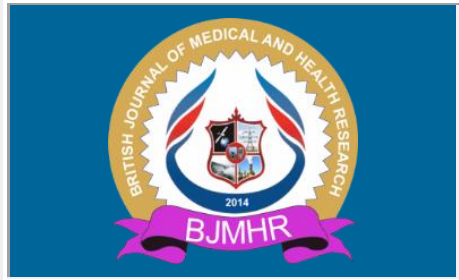

\title{
BJMHR
}

British Journal of Medical and Health Research

Journal home page: www.bjmhr.com

\section{Outcome of Laparoscopic Ovarian Drilling in Clinical \\ Presentations, and Conception in infertile Sudanese patients with Polycystic Ovarian Syndrome a cohorts study}

\author{
Asha Omer Ahmed ${ }^{1 *}$, Wisal Omer Mohamed Nabag ${ }^{2}$ \\ 1.Registrar in Obstetrics \& Gynecology, Sudan Medical Specialization Board, Khartoum, \\ Sudan
}

2. Professor of Obstetrics and Gynecology, Alzaiem Alazhari University P.O BOX 1432, Khartoum North 13311, Sudan. Mobile No: +2499121583983.

\section{ABSTRACT}

Polycystic ovary syndrome (PCOS) is a common complex; heterogeneous endocrine disorder characterized by irregular menses, hyperandrogenism, and infertility. To study the outcome of laparoscopic ovarian drilling in clinical presentations in form of cycle pattern, acne \& Hirsiutism in addition to their conception among infertile Sudanese patients with PCOS. A hospital based cohort study which was conducted in two hospitals in Khartoum state, Sudan; Omdurman Maternity Hospital \& Saad Abu Elela hospital from January to December 2018.Targeted 145 infertile patients diagnosed as PCOS based on Rotter-Dam criteria 2003 definition and who did not conceive after diet, lifestyle and clomiphene; underwent laparoscopic ovarian drilling (LOD).data was collected using semi-structured questionnaires before the drilling, then the patient was followed in 3 month time concerning the Clinical Presentations, and Conception 65(44.8\%) out of 145 infertile patients age was between 21-30 yrs, 67(46.2\%) were obese with BMI >30; 90 (62.1\%) of participants had irregular cycle., Hirsiutism was seen in 55 (37.9\%) and acne was observed in 89 (61.4\%). After laparoscopic drilling, $55.2 \%$ of patients had normal cycle pattern, amenorrhea \& menorrhagia dropped to $3.5 \%$ \& $11.7 \%$ respectively. About $46.2 \%$ had normal weight .Acne was seen in $32(22.2 \%) \&$ Hirsiutism present in 42(19.3\%) and 43 (29.6\%) get pregnancy, BMI, acne \& Hirsiutism before and after LOD were correlated using Chi square $\mathrm{P}$ value was $0.001,0.002$, and 0.007 respectively which was significant at $(\mathrm{P} \geq 0.05)$. The path physiology of PCOS improves, after LOD concerning clinical presentations, \& conception. Management of PCOS is essential to address patient concerns, prevent metabolic, \& endocrine complications.

Keywords: PCOS; Laparoscopy; Ovarian Drilling, Menstrual pattern, Acne, Hirsiutism, pregnancy

*Corresponding Author Email: wisnab3@yahoo.com

Received 05 May 2020, Accepted 26 May 2020

Please cite this article as: Ahmed AO et al., Outcome of Laparoscopic Ovarian Drilling in Clinical Presentations, and Conception in infertile Sudanese patients with Polycystic Ovarian Syndrome a cohorts study. British Journal of Medical and Health Research 2020. 


\section{INTRODUCTION}

Polycystic ovary syndrome (PCOS) is the most common endocrine disorder in women ${ }^{\mathbf{1}}$. Its prevalence among infertile women is $15-20 \%^{2}$. The etiology of PCOS remains unclear. A proposed mechanism for an ovulation and elevated androgen levels suggests that under the increased stimulatory effect of luteinizing hormone (LH) secreted by the anterior pituitary, stimulation of the ovarian theca cells is increased, these cells increase the production of androgens ${ }^{3}$.The clinical manifestation of PCOS varies from a mild menstrual disorder to severe disturbance of reproductive plus metabolic functions ${ }^{2}$. There are androgenic symptoms that will vary from patient to patient, such as Hirsiutism, acne, and/or alopecia ${ }^{\mathbf{1}}$; several diseases should be excluded to finally diagnose the patient with PCOS such as: congenital adrenal hyperplasia, non-classic adrenal hyperplasia. Management of women with PCOS depends on the symptoms ${ }^{2}$. More than $80 \%$ of women presenting with symptoms of androgen excess have PCOS. Hirsiutism is a common clinical presentation of hyperandrogenism occurring in up to $70 \%$ of women with $\mathrm{PCOS}^{4}$. The choice of treatment for women with PCOS depends on the symptoms with which a patient present. Symptoms typically fitted into three categories according to Badawy Menstruation related disorders; Androgen-related symptoms; and infertility.Weight loss are recommended as first-line therapy for the management of infertility in overweight and obese women with PCOS. In addition, obesity is associated with a reduced response to fertility treatments including clomiphene citrate, Gonadotropin, and laparoscopic ovarian diathermy ${ }^{3,5}$. An Observational study indicated that weight loss of 5-10\% can increase ovulation and pregnancies 5 Typically, oral contraceptive pills (OCPs) are first-line for pharmacologic management of Hirsiutism in premenopausal women ${ }^{6}$.Combined hormonal contraceptive $(\mathrm{CHCs})$ are the primary recommended treatment option for PCOS-related menstrual disorders and improved menstrual regularity ${ }^{2}$ Tang T \& his colleagues 2012 in a meta-analysis of randomized controlled trials illustrated that metformin improved ovulation rate and clinical pregnancy rate but not live birth rate when compared to placebo or no treatment ${ }^{7}$.Systematic review and meta-analysis compared laparoscopic ovarian drilling (LOD) with or without medical ovulation induction therapy to pharmacologic ovulation induction in clomiphene resistant PCOS and found no difference in ovulation rate or live birth rate between the groups ${ }^{\mathbf{8}}$. The study describes the outcome of laparoscopic drilling in clinical presentations, (menstrual pattern, BMI, acne, Hirsiutism) and conception among infertile Sudanese women with PCOS. 


\section{MATERIALS AND METHOD}

\section{Population and Study Procedures}

An observational, prospective cohort hospital-based study. The study was conducted in Omdurman Maternity Hospital, and Saad Abu Elela hospital, Khartoum, Sudan from January to December 2018 Targeted 145 infertile women diagnosed as PCOS using Rotterdam 2003 definition and who did not conceive after diet, lifestyle and clomiphene so laparoscopy was advised as diagnostic procedure for their infertility and management by ovarian drilling. The patients who have the following diseases were excluded from the study: hyperthyroidism, hypothyroidism, congenital adrenal hyperplasia (abnormal 17-hydroxyprogesterone level), pituitary insufficiency \& pituitary tumor. The patients were usually referred to Minimal Access Gynecological Centers (MAGS) by gynecologists from the two hospitals, other local hospitals, Family Planning Clinics and the private sector. Every patient was counseled and gave an informed consent prior to participating in the study, which had been approved by the Ethics Committee, Sudan Medical Specialized Board. Full history concerning their age, type and duration of their infertility, menstrual pattern, acne and Hirsiutism were reported then their weight and height were recorded and the body mass index (BMI) was calculated.

\section{Laparoscopy:}

Laparoscopy was confirmed PCO: Laparoscopy and dye test were performed as day surgery in the usual manner under general anesthesia. Pelvic adhesions per tubal, per ovarian, massive pelvic adhesions, frozen pelvis, per portal adhesions and endometriosis were reported. Tubal patency was confirmed with free spillage of Methylene blue dye from the fimbrial ends. At laparoscopy the ovaries have white thickened capsules and are often rounded. Bilateral ovarian drilling was performed with electro cautery using dipolar current at 40 strength and 40 seconds for each puncture and then clomiphene and metformin were prescribed for 3 months, with follow up regarding their menstrual pattern, BMI, acne, Hirsiutism and pregnancy. The data was analyzed using statistical Package for the Social Science (SPSS) and summarized using the percentage $\&$ Mean as well as Pearson Chi-square which was significant at $P$ value of $\geq 0.05$.

\section{RESULTS AND DISCUSSION}

The study included 145 infertile Sudanese women with PCOS. Their age was ranged between 20 to 45 years and 65(44.8\%) were between 21-30 years, 70 (48.4\%) were married for 2-5 years. Concerning cycle information were illustrated in Table 1; the age of Menarche102 (70.3\%) of studied population at 11-15 years. 90 (62.1\%) of participants had irregular cycle .Menstrual cycle pattern before \& after LOD in 3 month time was illustrated in Table 2 ; 81(55.2\%) had normal cycle , $41(28.3 \%)$ had Oligo menorrhea, 17 (11.7\%) had menorrhagia and $5(3.4 \%)$ had amenorrhea after LOD ; menstrual pattern in form of Oligomenorrheoa 
,amenorrhea\& menorrhagia before and after LOD were correlated using Chi square $\mathrm{P}$ value 0.001 which was significant $(\mathrm{P} \geq 0.05)$.,.BMI before \& after LOD in 3 month time was shown in Table 3 before LOD normal BMI was noticed in38(26.2) \&67(46.2\%) after while obese dropped from 40(27.6\%)before to16(11\%) after. Hirsiutism \& Acne among the study population;55 (37.9\%) complained of Hirsiutism while 89 (61.4\%) had acne as shown in Figure1.Forty two (19.3\%) \&32(22.0\%) of the study population were still complaining of Hirsiutism \& Acne in 3 month time after LOD respectively which was illustrated in Figure 2; BMI, acne \& Hirsiutism before and after LOD were correlated using Chi square P value were $0.001,0.002,0.007$ respectively which were significant $(P \geq 0.05)$. Figure 3 shown that 43 (29.6\%) out of 145 patient became pregnant after laparoscopic drilling; 18(41.7\%), 15 (35.4\%), $10(22.9 \%)$ within 6 weeks, 3 months \& 6 months respectively.

Table 1: Participants cycle information

\begin{tabular}{llcc}
\hline Variables & Details & Frequency & Percent \\
\hline Participants menarche & 10 yrs or less & 30 & $20.7 \%$ \\
& $11-15$ & 102 & $70.3 \%$ \\
& $16-20$ & 13 & $9 \%$ \\
& Total & 145 & $100 \%$ \\
cycle regularity & regular & 55 & $37.9 \%$ \\
& Irregular & 90 & $62.1 \%$ \\
& Total & 145 & $100 \%$ \\
\hline
\end{tabular}

Table 2: Menstrual cycle pattern before \& after LOD:-

\begin{tabular}{lllll}
\hline Cycle pattern & $\begin{array}{l}\text { Frequency Before } \\
\text { OLD }\end{array}$ & Percent & $\begin{array}{l}\text { Frequency After } \\
\text { OLD }\end{array}$ & Percent \\
\hline Normal & 50 & $34.5 \%$ & 81 & 55.2 \\
Oligo menorrhea & 29 & $20.7 \%$ & 41 & 28.3 \\
Amenorrhea & 15 & $10.3 \%$ & 6 & 3.5 \\
Menorrhagia & 50 & $34.5 \%$ & 17 & 11.7 \\
Total & 145 & 100 & 145 & 100.0 \\
\hline
\end{tabular}

Table 3: Participants body Mass Index (BMI) before\& after LOD:

\begin{tabular}{lll}
\hline BMI & $\begin{array}{l}\text { Frequency \& } \\
\text { \% Before LOD }\end{array}$ & $\begin{array}{l}\text { Frequency \& } \\
\text { \% after LOD }\end{array}$ \\
\hline Normal (18.5-24.9) & $38(26.2)$ & $67(46.2 \%)$ \\
Over weight $(25-29.9)$ & $67(46.2 \%)$ & $62(42.8 \%)$ \\
Obese ( $\geq 30)$ & $40(27.6 \%)$ & $16(11 \%)$ \\
Total & $145(100 \%)$ & $145(100 \%)$ \\
\hline
\end{tabular}


- present absent

$89(61.40 \%)$

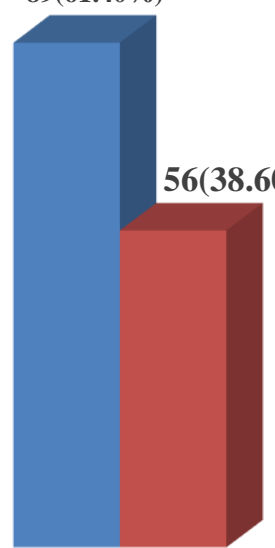

Acne
$90(62.10 \%)$

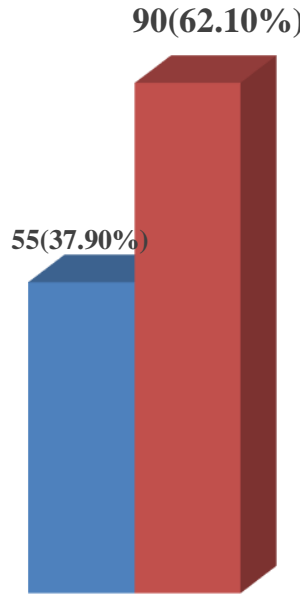

Hirsiutism

Figure 1: Presence of Hirsiutism and acne $(n=145)$ at presentation

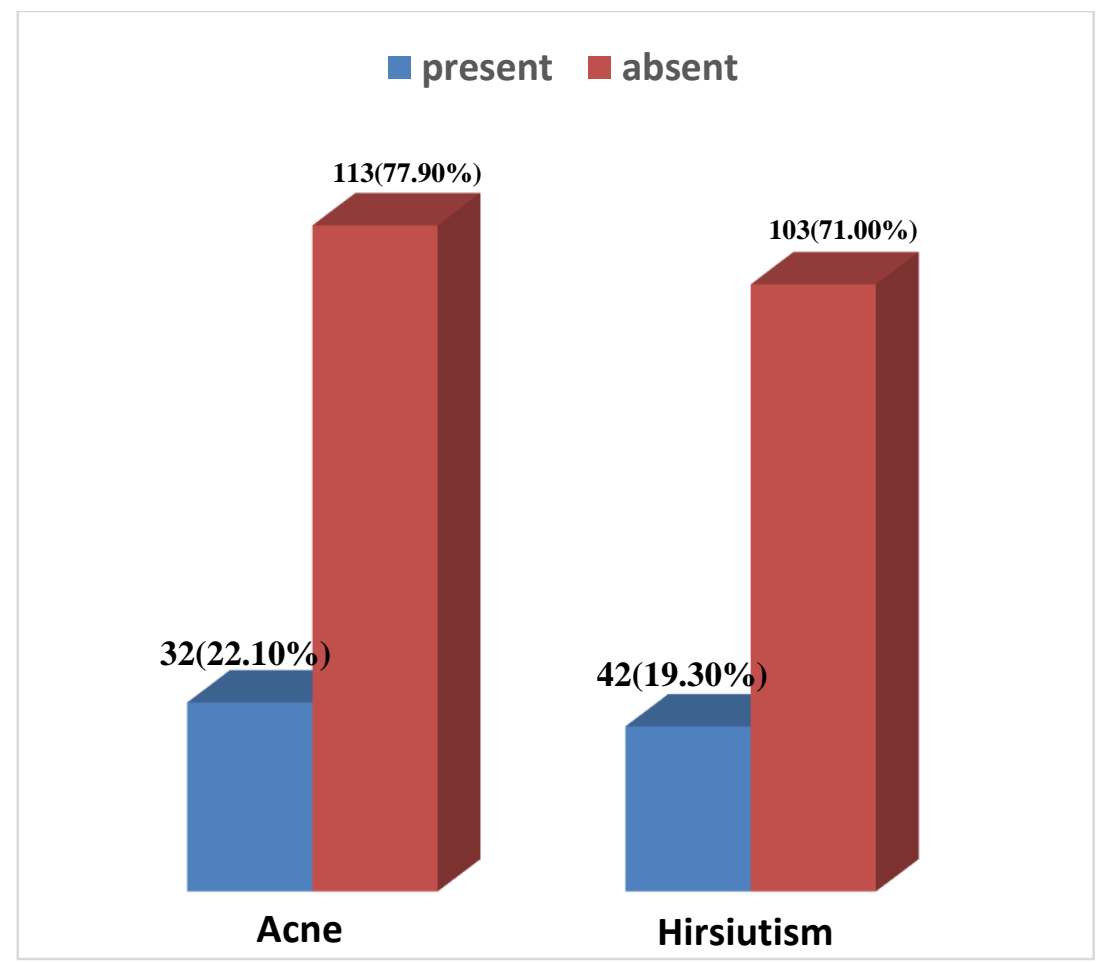

Figure 2: Acne and Hirsiutism after LOD 


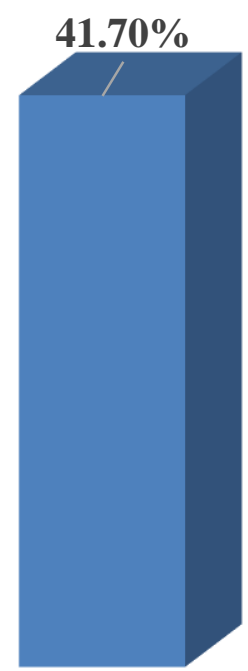

6 weeks

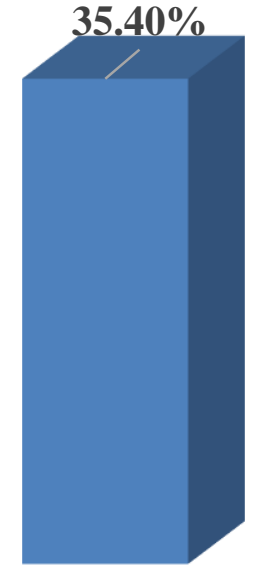

3 months

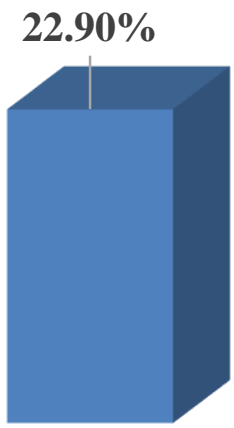

6 months

Figure 3: Period till pregnancy happened after laparoscopic drilling $(n=43)$

\section{DISCUSSION}

The study was described the outcome of follow-up of 145 women who had PCOS and treated by laparoscopic ovarian drilling, concerning, clinical presentations \& conception in the 3months time following LOD. Regarding menstrual cycle pattern at presentation 90(62.1\%) had irregular cycle, , 35.2\% had normal amount of loss, 20.7\% had oligo menorrhea $10.3 \%$ had amenorrhea $\& 34.5 \%$ had menorrhagia as stated by Hart R. who reported that menstrual disturbances commonly observed in PCOS include Oligomenorrheoa, amenorrhea, and prolonged erratic menstrual bleeding 9 . after LOD $30.0 \%$ of study population showed irregular cycle: normal amount of loss in $55.2 \%$, Oligo menorrhea $28.3 \%$, amenorrhea dropped to $3.5 \%$ \& menorrhagia dropped to $11.7 \%$ in addition to menstrual pattern in form of Oligomenorrheoa ,amenorrhea\& menorrhagia before and after LOD were correlated using Chi square $\mathrm{P}$ value 0.001 which was significant (P 0.05). Wisal O. M. Nabaget.al had a study among Sudanese patients with PCOs, they found that the clinical features of PCOS among the study population were prolonged cycle in 53(86\%); $60 \%$ of the patients regained regular cycle after the LOD because it decreases the level of androgen ${ }^{10}$. Our results were consistent with the results of Bargiota A and other experts they found the patients with regular menstrual cycles increased significantly from $8 \%$ before LOD to $67 \%$ post-operatively and they concluded that LOD produces improve the menstrual regularity and reproductive performance ${ }^{11}$. The results of the study and literature appeared that LOD has a beneficial impact on the menstrual cycle regularity since the proportions of women with normal menstrual cycles at follow-up visits 
after surgery were significantly greater than before $i^{12,11}$ In our study population, excess androgens in term of acne and Hirsiutism were presented in $61.4 \%$ and $37.9 \%$ and of studied patients respectively, LOD produced improvement in acne \& Hirsiutism, in follow up visits within 3 months time, acne was presented in only $22.21 \%$ \& Hirsiutism in $19.3 \%$ The acne \& Hirsiutism before \& after LOD were found to be related to each other evidenced by P value of $0.002, \mathrm{P}$ value of 0.007 respectively , Fauser B \& his collogues 2012 had similar results, they investigated 228 patients presented with unwanted hair, and the study agreed on that treatment with LOD of POCs will inconsequently disappear or minimize the androgens manifestations. Sudanese study illustrated that Hirsiutism in 45 (73.5\%) and acne in 42 (70\%) were decreased after LOD ${ }^{10}$ Weight loss is recommended as first-line therapy for the management of infertility in overweight and obese women with PCOS; in the study population 70(48.4\%) of women were overweight \&40(27.6\%) were obese \&after LOD that the overweight constituted $67(46.2 \%) \&$ the obese were dropped to $16(11 \%)$ our results constitute with YiLDiz B, \& his colleges whom were studied, the Impact of obesity on the risk for polycystic ovary syndrome and illustrated that LOD effect the patient's body composition ${ }^{\mathbf{1 3}}$. Chronic an ovulation in women with PCOS is usually associated with menstrual irregularities; similar to our study several authors have reported that PCOS patients have apparently 'irregular' menstrual cycles9, 14,15 Dewailly D. et al. investigated 240 PCOs patients undergoing LOD between 2008 and 2010 for exploration of hyperandrogenism (HA) menstrual disorders and/or infertility; Spontaneous ovulation was happened in 71/100 patients (71.0\%) after LOD. the study related it to the significantly drop of luteinizing hormone and androstenedione and their clinical presentation ${ }^{14}$. Another study recommended to perform laparoscopic ovarian drilling in patients with high luteinizing hormone and androstenedione levels ${ }^{\mathbf{1 6}}$. Regarding pregnancy, the chance of becoming pregnant depends on ovulation. The study population did not conceive after diet, lifestyle and clomiphene so they underwent laparoscopy and ovarian drilling then the results showed that the overall, 43(29.1\%) of 145 women conceived spontaneously following LOD; 18, 15 \& 10 cases within 6 weeks,3months \& 6 months respectively. This high rate of pregnancy might be explained by the fact that among our study population there was mark reduction in weight, because the weight loss of 5\%-10\% can increase ovulation and pregnancies ${ }^{17}$. therefore, we can conclude that LOD has beneficial impact on the reproductive performance immediately after LOD and then declined gradually, the good outcome up to one year after; the same outcome of Farquhar $C \&$ his colleagues whom were concluded that After LOD, 49\% women conceived spontaneously during the first year and 38\% during mediumand long-term follow-up ${ }^{11}$ This result was consistent with other report, it showed that 125 patients who underwent LOD, 40 women became spontaneously pregnant after $\mathrm{LOD}^{\mathbf{1 8}}$. Another study showed that pregnancy rate among study group was $35 \%$ within the first 9 months ${ }^{10}$. 


\section{CONCLUSION:}

Polycystic ovary syndrome (PCOS) is a common complex; heterogeneous endocrine disorder characterized by irregular menses, hyperandrogenism, and infertility,. The study included 145 infertile Sudanese patients with PCOS. Their age was ranged between 20 to 45 years and $65(44.8 \%)$ were between 21-30 years, overweight, married, had irregular cycle in 90(62.1\%). Acne in 89(61.4\%) \& 55(37.9\%) with Hirsiutism. After laparoscopic drilling, majority regained normal cycle pattern, amenorrhea \& menorrhagia, Acne, Hirsiutism \& BMI were dropped in addition 43 (29.6\%) get spontaneous pregnancy. The path physiology of PCOS improves, after LOD with good outcome regarding clinical presentations and conception..

\section{DISCLOSURE}

Wisal Omer Mohamed Nabag, and Asha Omer Ahmed, declared that they have no conflict of interest.

\section{REFERENCES}

1. Goodarzi MO, Dumesic DA, Chazenbalk G, Azziz R. Polycystic ovary syndrome: etiology, pathogenesis and diagnosis. Nat Rev Endocrinol. 2011; 7:219-231.

2. Bates GW, Propst AM. Polycystic ovarian syndrome management options. Obstet Gynecol Clin North Am. 2012; 39(4):495-506.

3. Polycystic ovary syndrome. Obstet Gynecol. 2009;114(4):936-949

4. Fauser B, Tarlatzis B, Rebar R, et al. Consensus on women's health aspects of polycystic ovary syndrome (PCOS): the Amsterdam ESHRE/ASRM-Sponsored 3rd PCOS Consensus Workshop Group. Fertil Steril. 2012; 97(1):28-38. e25.

5. Susan M Sirmans and Kristen A Pate. Epidemiology, diagnosis, and management of polycystic ovary syndrome. Clin Epidemiol. 2014;6: 1-13. doi: 10.2147/CLEP.S37559

6. Badawy A, Elnashar A. Treatment options for polycystic ovary syndrome. Int J Womens Health. 2011; 3:25-35.

7. Tang T, Lord JM, Norman RJ, Yasmin E, Balen AH. Insulin-sensitizing drugs (metformin, rosiglitazone, pioglitazone, D-chiroinositol) for women with polycystic ovary syndrome, oligo amenorrhoea and subfertility. Cochrane Database Syst Rev. 2012; 5:CD003053.

8. Lowenstein E. Diagnosis and management of the dermatologic manifestations of the polycystic ovary syndrome. Dermatol Ther. 2006; 19(4):210-223.

9. Hart R. Definitions, prevalence and symptoms of polycystic ovaries and the polycystic ovary syndrome. In: Allahbadia GN, Agrawal R, editors. Polycystic Ovary Syndrome. Kent, UK: Anshan, Ltd; 2007. pp. 15

10. Wisal O. M. Nabag, Eshraga A. Farajalla and Mohamed A. A. El Sheikh. Insulin 
Resistance in Infertile Sudanese Patients with Poly Cystic Ovarian Syndrome(PCOS) at Laparoscopy. British Journal of Medicine \& Medical Research, 2014 4(3): 889-897

11. Farquhar C, Lilford RJ, Marjoribanks J, Vandekerckhove P. Laparoscopic 'drilling' by diathermy or laser for ovulation induction in an ovulatory polycystic ovary syndrome. Cochrane Database Syst Rev. 2007;18(3):CD001122.

12. Perales-Puchalt A, Legro RS. Ovulation induction in women with polycystic ovary syndrome. Steroids. 2013;78:767-772

13. YiLDiz B, Knochenhauer ES, Azziz R. Impact of obesity on the risk for polycystic ovary syndrome. J Clin Endocrinol metab. 2008;93(1):162-168

14. Dewailly D, Gronier H, Poncelet E, et al. Diagnosis of polycystic ovary syndrome (PCOS): revisiting the threshold values of follicle count on ultrasound and of the serum AMH level for the definition of polycystic ovaries. Hum Reprod. 2011;26(11):31233129.

15. Dokras A, Clifton S, Futterweit W, WiLOD R. Increased risk for abnormal depression scores in women with polycystic ovary syndrome: a systematic review and metaanalysis. Obstet Gynecol. 2011;117(1):145-152.

16. Bargiota A, Diamanti-Kandarakis E. The effects of oLOD, new, and emerging medicines on metabolic aberrations in PCOS. Ther Adv Endocrinol Metab. 2012;3(1):27-47.

17. Susan M Sirmans and Kristen A Pate. Epidemiology, diagnosis, and management of polycystic ovary syndrome. Clin Epidemiol. 2014; 6: 1-13. doi: 10.2147/CLEP.S37559

18. Johannes Ott et. al. Pregnancy outcome in women with polycystic ovary syndrome comparing the effects of laparoscopic ovarian drilling and clomiphene citrate stimulation in women pre-treated with metformin: a retrospective study. Reprod Biol Endocrinol. 2010; 8: 45. Published online 2010 May 13. doi: 10.1186/1477-7827-845. PMCID: PMC2885401

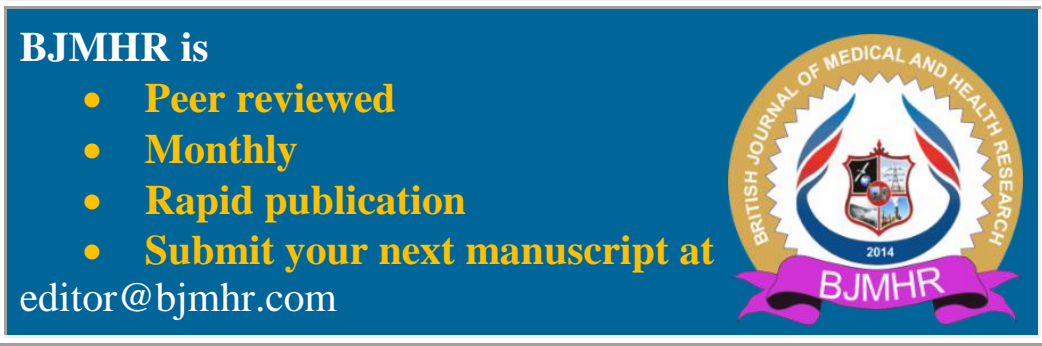

